\title{
Reuse of a Damaged Permanent Magnet Synchronous Motor for Torque Ripple and Acoustic Noise Elimination using a Novel Repetitive Observer
}

\author{
Mi Tang, Shafiq Odhano, Andrea Formentini, Pericle Zanchetta \\ Power Electronic, Machine and Control (PEMC) group \\ University of Nottingham \\ Nottingham, UK \\ mi.tang2@nottingham.ac.uk
}

\begin{abstract}
A permanent magnet synchronous motor (PMSM) has its bearing damaged and is irreversibly demagnetized due to overcurrent. Due to the changes in its electromagnetic configuration, the motor suffers from extremely high torque ripple, which produces intolerable speed ripple and acoustic noise. The aim of this paper is to evaluate if a repetitive observer (RO) can be used to smooth the rotational speed and suppress acoustic noise. The RO is functionally the same as a repetitive controller ( $\mathrm{RC})$, but is preferred due to its simplicity of tuning. Its effectiveness of reducing acoustic noise will be evaluated in this paper for the first time. Experimental test results show that the speed ripple and acoustic noise are reduced significantly. The work opens the possibility of reusing the damaged motor and still achieve high performance. The RO can also be applied to enhance the fault tolerance capability of a healthy motor.
\end{abstract}

Keywords-demagnetization, acoustic noise, fault-tolerance, repetitive observer, torque ripple reduction

\section{INTRODUCTION}

Permanent magnet synchronous motor (PMSM) is preferred over the induction motor due to its high efficiency. On one hand, the use of permanent magnet benefits the highpower density, on the other hand, the permanent magnet material may suffer from demagnetization as the operation temperature increases. In severe conditions, the demagnetization caused by overcurrent, overheating or short circuits can be irreversible [1].

To prevent the demagnetization from happening, many demagnetization models have been proposed to allow online monitoring of the magnets. The comparison work is available in [1]. Authors in [2] proposed a method to detect demagnetization by acoustic noise.

However, once irreversible demagnetization has happened, the broken motor is normally replaced and disposed. Although authors in [3] have proposed a current compensation scheme to cancel the torque ripple due to demagnetization, it is barely discussed in existing literature that if eventually the damaged motor can be reused with proper compensations.

A lab-used PMSM for servo application that has been damaged due to overcurrent is discussed in this paper. More analysis on the damage will be presented in Section IV. As a result, the motor suffers from exceedingly high second order (with respect to the electrical frequency) torque ripple, which produces intolerable speed ripple and acoustic noise. Hence, the aim of this paper is to smooth the rotational speed and reduce the audible noise by applying a recently developed repetitive observer ( $\mathrm{RO})$, and evaluate its effectiveness. The $\mathrm{RO}$ is considered suitable for this application because of the following benefits:

- $\mathrm{RO}$ is functionally the same as a repetitive controller (RC) $[4,5]$, which is a promising tool that can self-learn the periodic disturbance. Therefore, no pre-knowledge of the ripple needs to be measured. The disturbance produced by the demagnetization can be online observed and canceled.

- RO is structurally the same as a high-dimension disturbance observer [6], therefore, it can be designed following the well-known separation principle. That is, the RO can be added to an existing control loop without affecting the system stability.

- Since torque disturbance [7] is often present even for a healthy motor due to harmonics in the inverter, cogging effect, non-sinusoidal flux distribution, current sensor offsets/scaling errors and mechanical misalignments, the RO can be used also in the healthy condition, and once the demagnetization is happened, the RO can adapt itself and maintains the high performance. Hence, the faulttolerance capability and robustness of the PMSM can be enhanced.

The effectiveness of the RO on reducing acoustic noise is evaluated in this paper for the first time. Experimental test results have shown that the significant speed ripple and audible noise reduction have been achieved. Also, the performance of the damaged motor with compensation is comparable with the healthy version of the same motor.

\section{SIMILARITIES BETWEEN RC AND RO}

Block diagram of a conventional $\mathrm{RC}$ with additional correction term can be seen from Fig. 1a. Where, $L_{r c}$ is the gain of RC, $z^{-N}$ is the delay chain in RC, $N$ is the ratio between the sampling frequency and the target ripple frequency, $G_{f}(z)$ is known as the stability filter for canceling the delays produced by the plant and any measurement delay, which can be chosen as, for example, the reverse of the plant. $Q_{f}(z)$ is namely the robustness filter for attenuating the high frequency noise, of which the simplest choice is a forgetting factor (i.e. a constant value from zero to one).

Considering the state-space equation, the mechanical plant of PMSM with periodic disturbance is as given in (1) and Fig. 1b. The inner current loop is ignored in the diagram because it is not the focus of this paper. Also, it is negligible since its dynamics is much faster than the mechanical system. 


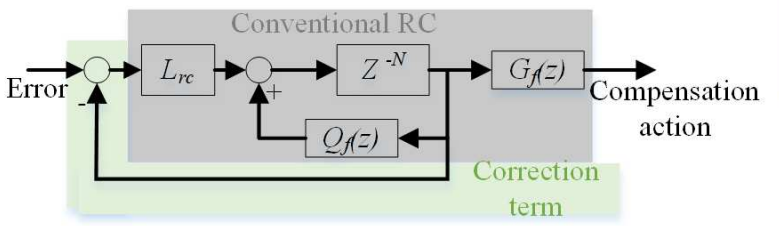

(a) Conventional RC with correction term

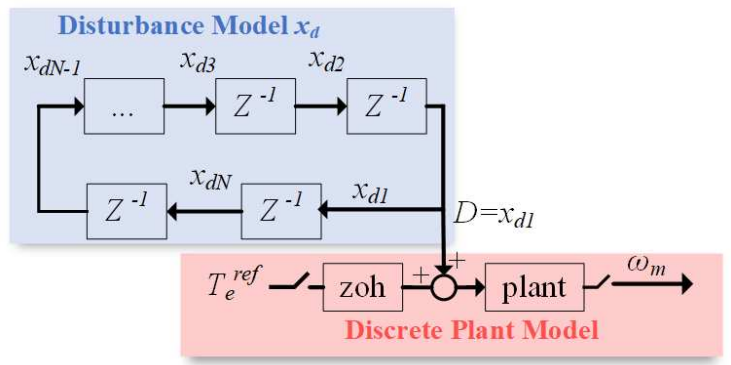

(b) Plant with disturbance model

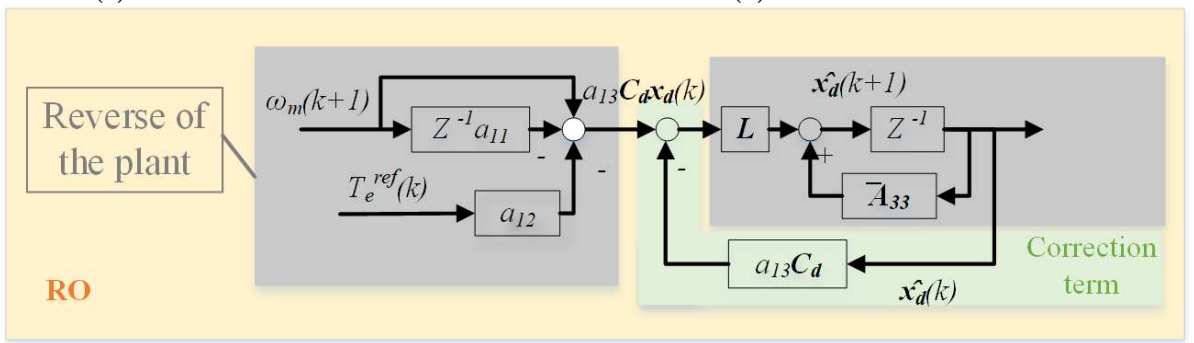

(c) $\mathrm{RO}$

Fig.1 The similarity between conventional RC and RO

$$
\begin{aligned}
& {\left[\begin{array}{c}
w_{m}(k+1) \\
T_{e}(k+1) \\
\boldsymbol{x}_{\boldsymbol{d}}(k+1)
\end{array}\right]=\left[\begin{array}{ccc}
a_{11} & a_{12} & a_{13} \boldsymbol{C}_{\boldsymbol{d}} \\
0 & 0 & 0 \\
\mathbf{0} & \mathbf{0} & \boldsymbol{A}_{\boldsymbol{d}}
\end{array}\right]\left[\begin{array}{c}
w_{m}(k) \\
T_{e}(k) \\
\boldsymbol{x}_{\boldsymbol{d}}(k)
\end{array}\right]+} \\
& {\left[\begin{array}{l}
0 \\
1 \\
\mathbf{0}
\end{array}\right] T_{e}^{r e f}(k)}
\end{aligned}
$$

The periodic disturbance can be expressed using a $N$ dimension state vector $\boldsymbol{x}_{\boldsymbol{d}}$ as in (2) and Fig. $1 \mathrm{~b}$.

$$
\left\{\begin{array}{c}
\boldsymbol{x}_{\boldsymbol{d}}(k+1)=\boldsymbol{A}_{\boldsymbol{d}} \boldsymbol{x}_{\boldsymbol{d}}(k) \\
D(k)=\boldsymbol{C}_{\boldsymbol{d}} \boldsymbol{x}_{\boldsymbol{d}}(k)
\end{array}\right.
$$

and, $\boldsymbol{x}_{\boldsymbol{d}}(k)=\left[\begin{array}{c}x_{d 1}(k) \\ x_{d 2}(k) \\ \ldots \\ x_{d N-1}(k) \\ x_{d N}(k)\end{array}\right], \boldsymbol{A}_{\boldsymbol{d}}=\left[\begin{array}{cccccc}0 & 1 & 0 & \ldots & 0 & 0 \\ 0 & 0 & 1 & \ldots & 0 & 0 \\ \ldots & \ldots & \ldots & \ldots & \ldots & \ldots \\ 0 & 0 & 0 & \ldots & 0 & 1 \\ 1 & 0 & 0 & \ldots & 0 & 0\end{array}\right]$,

$\boldsymbol{C}_{\boldsymbol{d}}=\left[\begin{array}{llllll}1 & 0 & 0 & \ldots & 0 & 0\end{array}\right]$

According to the concept of DO, the disturbance state vector $\boldsymbol{x}_{\boldsymbol{d}}$ can be observed as in Fig. 1c. It can be seen from Fig. 1c that the left part of RO is equivalent to the reverse of the plant, and therefore equivalent to $G_{f}(z)$. Whereas, the forgetting factor $Q$ is included in $\overline{\boldsymbol{A}}_{\boldsymbol{d}}$ as in (3), and $\boldsymbol{L}=\left[\begin{array}{lll}0 & 0 & 0\end{array}\right.$ $\left.\ldots L_{r c}\right]^{\mathrm{T}}$ is the observer gain.

Overall, the RO in Fig. 1c is equivalent to the RC with a correction term in Fig. 1a. The proposed speed loop control diagram for the damaged motor is drawn as in Fig. 2. Only two parameters, $L_{r c}$ and $Q$ need to be tuned in the RO. According to [8], it is recommended to set $Q=1$ and $L_{r c}$ to a small value to reduce the interaction between the speed proportional-integral (PI) regulator and RO. It has also been mathematically proven in [8] that the PI can be designed independently from the RO. Overall, the PI controller has been designed to obtain $450 \mathrm{~Hz}$ speed loop bandwidth, and the gain of RO $L_{r c}$ is set to 0.05 .

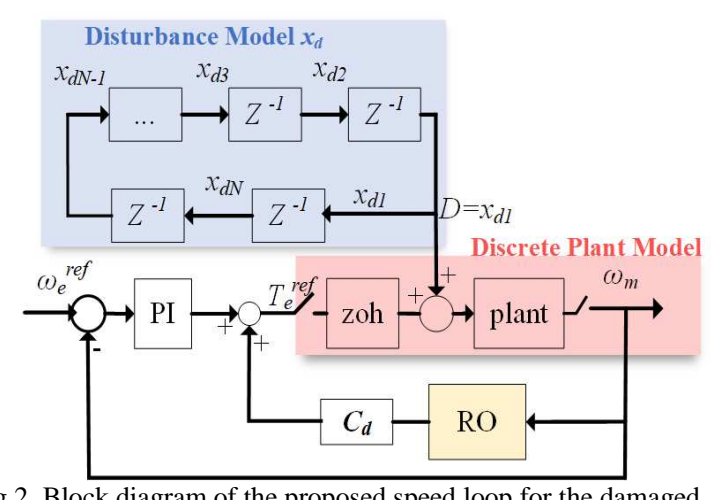

PMSM

\section{ISSUES IN PRACTICAL IMPLEMENTATION}

For practical implementation, the following issues have been considered, which are not shown in the control diagram. These issues have been discussed in [9]. Briefly:

- The acquisition of speed $\omega_{\mathrm{m}}$ :

The position is measured from a 17-bit encoder. The mechanical speed is calculated from the measured position. A low-pass Finite Impulse Response (FIR) filter is used in the speed calculation to remove the quantization error in the position.

- Adapting the RO to variable speed:

Following the concept of angle-based RC proposed in [7], the RO is implemented with respect to the rotor position in [9] since the disturbance torque is rotorposition-based.

- The robustness of the RO to speed and load transients:

Results in [9] have confirmed that the speed loop PI is responsible for the transient response, and the observer will not disturb the PI controller.

- The robustness of the RO against mechanical parameter variations:

Analysis in [9] shows that the performance of RO will degrade if the mechanical parameters are larger than the real parameters. However, the detuned mechanical parameters will not cause any instability. In this paper, the mechanical parameters are set according to the datasheet. 


\section{EXPERIMENTAL TEST RESULTS}

The machine and control parameters are shown in Table I. The control algorithms are implemented on a high performance FPGA/DSP platform [10]. The test rig is as shown in Fig. 3. It is worth noting that the $d$ and $q$ axis inductances after the damage become $1.7 \mathrm{mH}$ and $3.3 \mathrm{mH}$, respectively. However, the parameters set in the controller during the tests are kept as their datasheet values as in Table I. The intended controller is robust against such inductances variation. The size of the damaged motor is larger than the healthy motor because the damaged motor is integrated with an electrical brake.
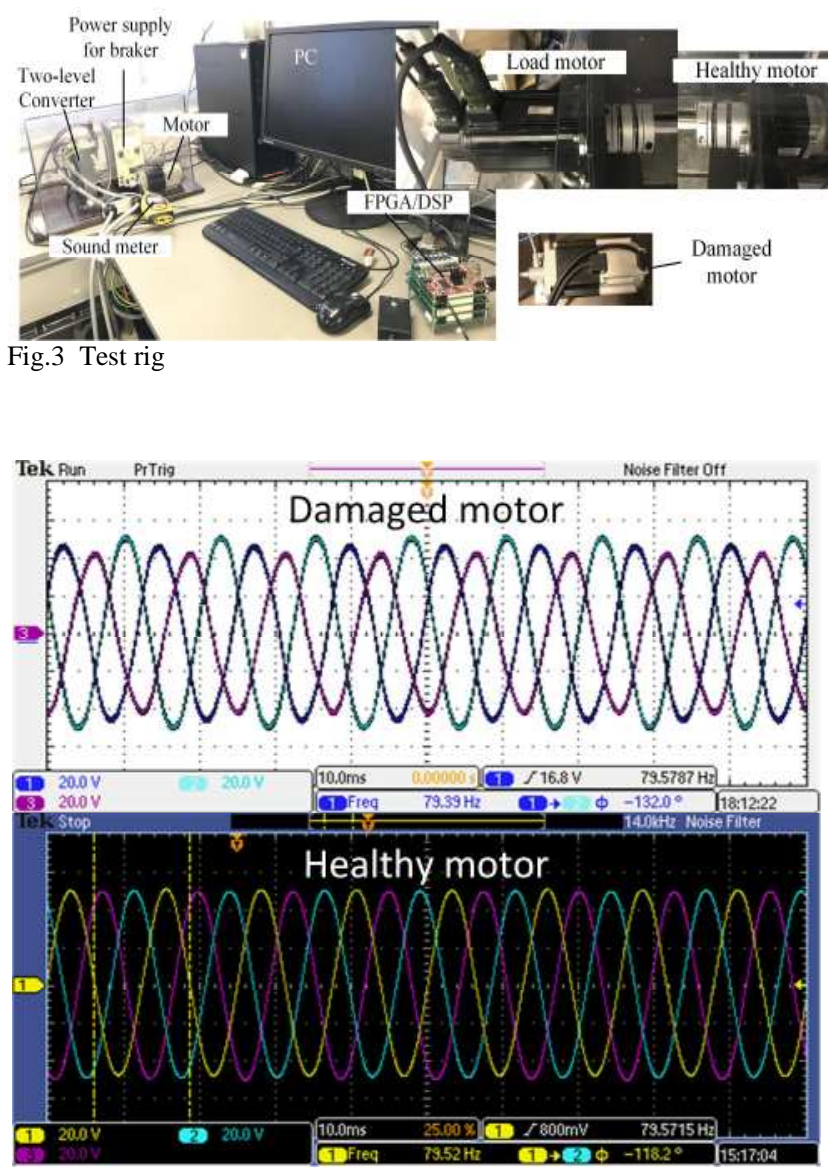

(a) Line-to-line voltage when driven from load side

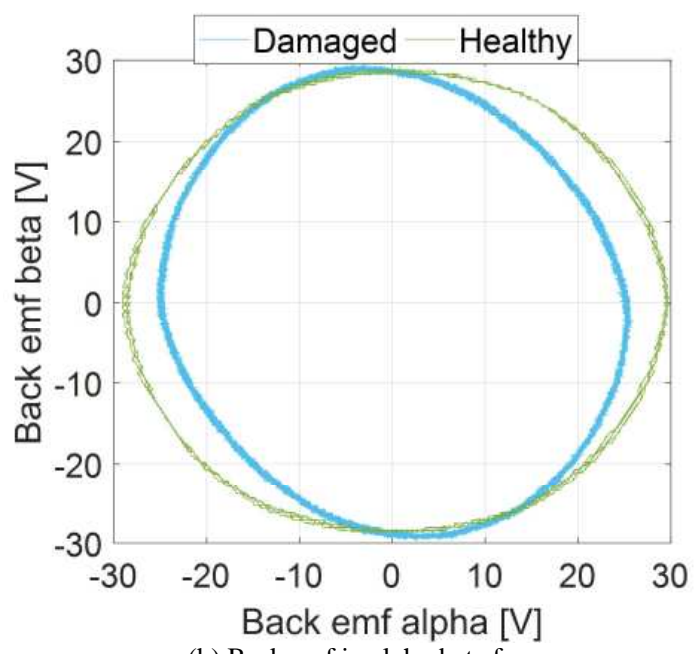

Fig.4 Back emf at $125 \mathrm{rad} / \mathrm{s}$.
TABLE I. HEALTHY MACHINE AND CONTROL PARAMETERS

\begin{tabular}{|c|c|c|c|}
\hline Parameter & Value [Unit] & Parameter & Value [Unit] \\
\hline $\begin{array}{c}\text { Number of } \\
\text { pole pairs }\end{array}$ & 4 & $\begin{array}{c}\text { dq-axis } \\
\text { inductances } \mathrm{L}_{\mathrm{dq}}\end{array}$ & $2.6[\mathrm{mH}]$ \\
\hline $\begin{array}{c}\text { Stator } \\
\text { resistance }\end{array}$ & $0.43[\mathrm{Ohms}]$ & Magnetic flux & $0.0589[\mathrm{~Wb}]$ \\
\hline $\begin{array}{c}\text { Friction factor } \\
\text { B }\end{array}$ & $\begin{array}{c}0.8 \mathrm{e}^{-3} \\
{[\mathrm{Nms} / \mathrm{rad}]}\end{array}$ & $\begin{array}{c}\text { Moment of } \\
\text { inertia } \mathrm{J}\end{array}$ & $1.06 \mathrm{e}^{-4}\left[\mathrm{kgm}^{2}\right]$ \\
\hline $\begin{array}{c}\text { Forgetting } \\
\text { factor Q }\end{array}$ & 1 & $\begin{array}{l}\text { Observer gain } \\
\text { matrix L }\end{array}$ & {$\left[\begin{array}{lllll}0 & 0 & \ldots & 0 & 0.05\end{array}\right]^{\mathrm{T}}$} \\
\hline
\end{tabular}

\section{A. Test 1: Back emf}

To analyse the damage, a load motor has been used to drive the damaged motor at constant speed, the back emf waveforms are recorded and compared with the healthy motor. The lineto-line voltages at $125 \mathrm{rad} / \mathrm{s}$ are shown in Fig. 4a. The voltages are converted into the phase voltages in alpha-beta frame and plotted in Fig. 4b. Results show that the back emf of the damaged motor is unbalanced and has shrunk due to demagnetization.

\section{B. Test 2: Speed Ripple Suppression}

The test is carried out by controlling the motor at $500 \mathrm{rpm}$ with no load. Fig. 5a and Fig. 5b show the speed with and without the RO for compensation, whereas Fig. 5c show the FFT results of the speed with and without compensation.

It can be seen from Fig. 5a and Fig. 5b that the peak to peak value of speed ripple is reduced significantly from -11.4 $\sim+15.5 \mathrm{rpm}$ to $-1.7 \sim+1.5 \mathrm{rpm}$ with the compensation. Correspondingly, the significant speed ripple reduction can also be seen from the frequency domain in Fig. $5 \mathrm{c}$.

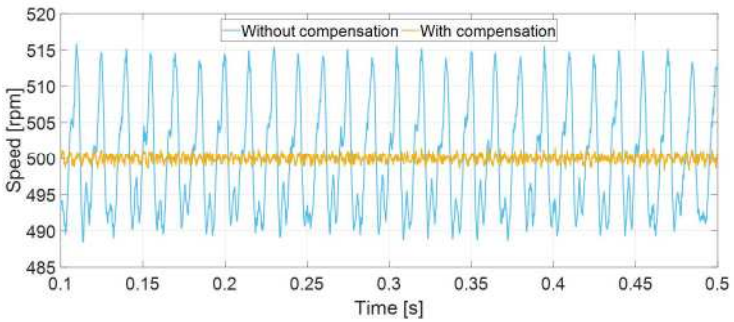

(a) Speed

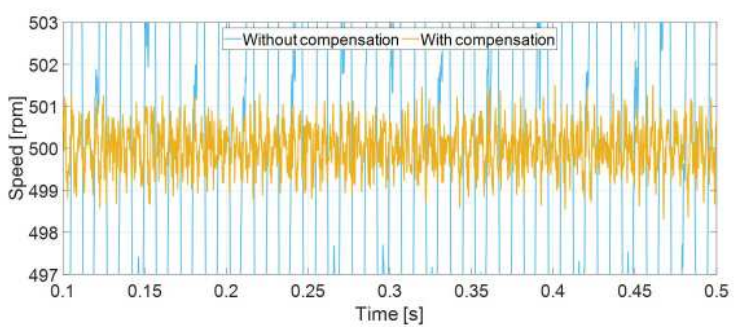

(b) Speed (Zoom-in)

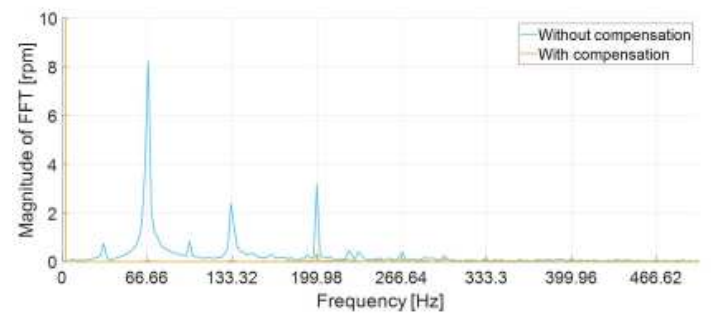

(c) FFT results

Fig.5 Speed ripple of the damaged motor with and without compensation at $500 \mathrm{rpm}$. 


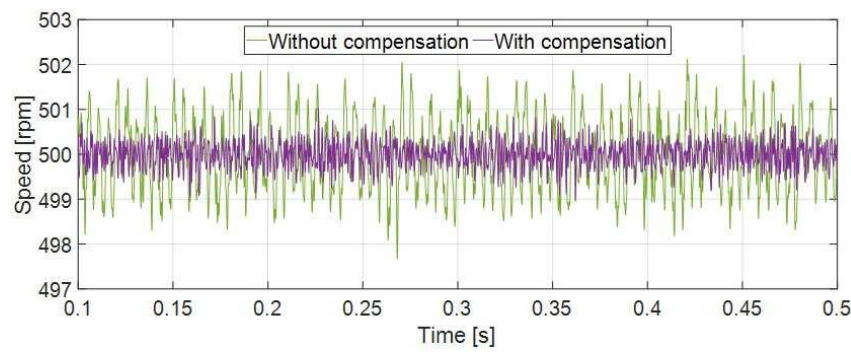

(a) Speed

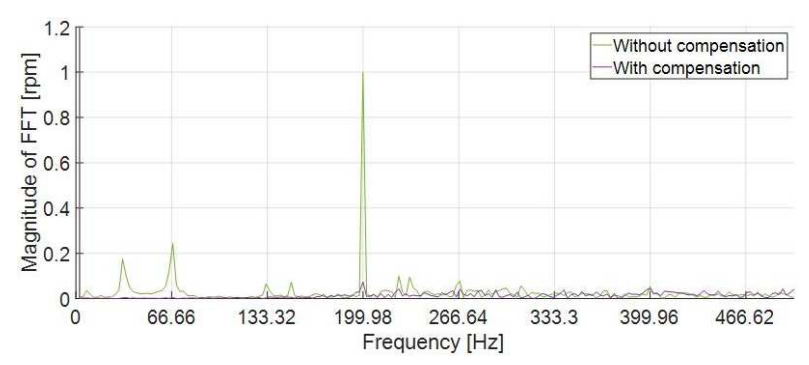

(b) FFT results

Fig.6 Speed ripple of the healthy motor with and without compensation at $500 \mathrm{rpm}$.

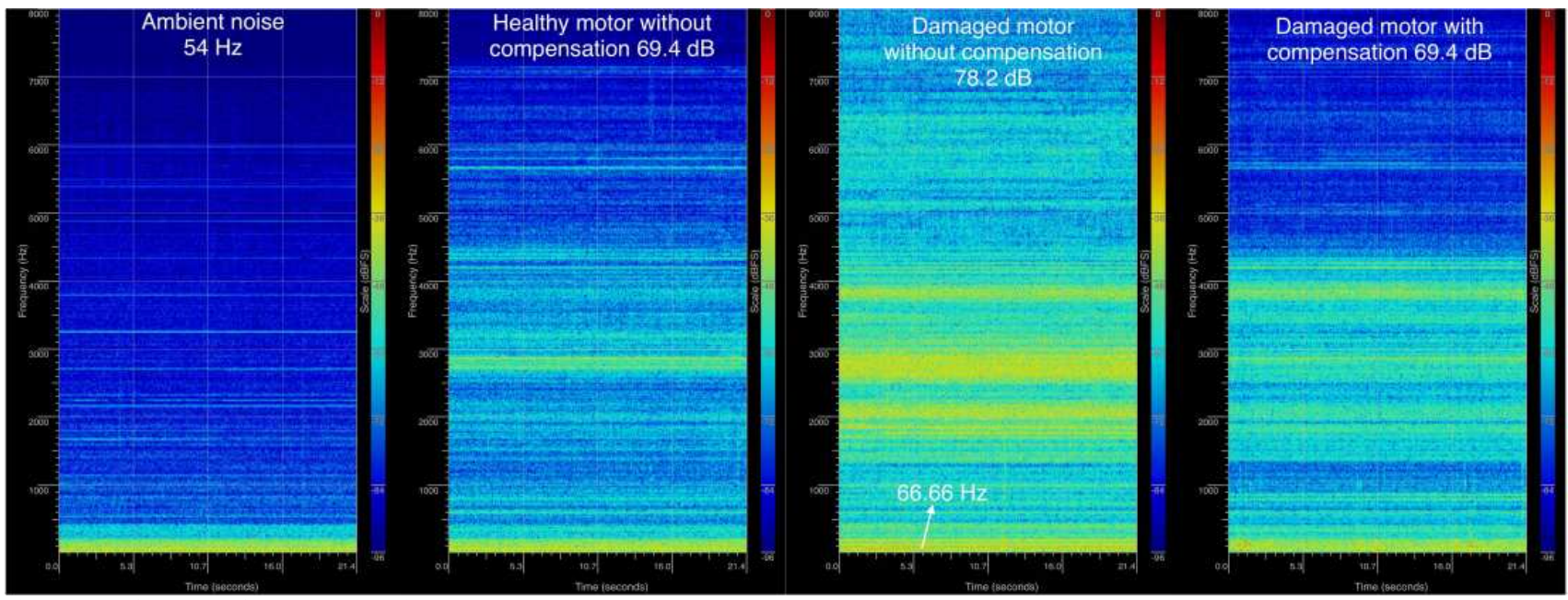

Fig.7 Waterfall plots of the acoustic noise at $500 \mathrm{rpm}$.

Considering the fundamental electrical frequency at 500 rpm for a 4 pole-pair PMSM is $33.33 \mathrm{~Hz}$. As shown in Fig. 5c, the key effect of the damage is that exceedingly high second (i.e. $66.66 \mathrm{~Hz}$ ) harmonic speed ripple is produced.

The same test has been repeated using the healthy motor, and the results are shown in Fig. 6. It can be seen that the proposed RO can not only work with the damaged motor, but also with the healthy motor. With the healthy motor, speed ripple has been reduced from $\pm 2.2 \mathrm{rpm}$ to $\pm 1 \mathrm{rpm}$. Comparing Fig. 5 and Fig. 6, after compensation, the damaged motor rotates even smother than the healthy motor without compensation.

\section{Test 3: Acoustic Noise Reduction}

Despite of the demagnetization, the damaged motor also suffers from bearing damage. As a result, audible noise occurs even when rotating the motor shaft by hand.

The acoustic noise is measured during Test 2. The waterfall plots of the ambient noise, and the noise with/without compensation are shown in Fig. 7, meanwhile, the noise level measured from a commercial sound meter is also annotated in each plot.

The ambient noise is measured when the machine is not in operation. The noise due to operation is superimposed on the ambient noise, so without compensation the noise is $24.2 \mathrm{~dB}$ and after compensation, it is $15.4 \mathrm{~dB}$. So, the noise reduction is $8.8 \mathrm{~dB}$ before and after the compensation.

It is also worth noting that there is no significant noise change for the healthy motor before and after compensation. This confirms that the proposed RO will not cause noise problem for the healthy motor.
The proposed RO targets ripple below $1000 \mathrm{~Hz}$. Hence, the high frequency ripple as shown in Fig. 7 cannot be eliminated. However, such high frequency ripple will not be present in the speed due to the low-pass nature of the mechanical system. As a result, the damaged motor with compensation and the healthy motor have the same noise measurement (i.e. $69.4 \mathrm{~dB}$ ).

\section{CONCLUSION}

The aim of this paper is to evaluate the effectiveness of the $\mathrm{RO}$ on smoothing the speed ripple and reducing the acoustic noise caused by damaged bearing and irreversible demagnetization. Experimental tests have shown that significant speed ripple and noise reductions are achieved.

This novel work is important because it opens the possibility of reusing the damaged motor and still achieve high performance such as in servo applications. For heathy motor, the technology can also help enhancing the fault-tolerance capability of the PMSM by continuous learning about the speed ripple arising from demagnetization and compensating it.

The authors believe that this work transcends the state-ofthe-art of PM servomotors' diagnostics and reuse, and opens new avenues for research in this direction.

\section{ACKNOWLEDGMENT}

This work is financially supported by Shenzhen Best Motion Technology Ltd. 


\section{REFERENCES}

[1] S. Hamidizadeh, N. Alatawneh, R. R. Chromik, and D. A. Lowther, "Comparison of Different Demagnetization Models of Permanent Magnet in Machines for Electric Vehicle Application," IEEE Transactions on Magnetics, vol. 52, no. 5, pp. 1-4, 2016.

[2] M. Zhu, W. Hu, and N. C. Kar, "Acoustic Noise-Based Uniform Permanent-Magnet Demagnetization Detection in SPMSM for HighPerformance PMSM Drive," IEEE Transactions on Transportation Electrification, vol. 4, no. 1, pp. 303-313, 2018.

[3] X. Xiao and C. Chen, "Reduction of Torque Ripple Due to Demagnetization in PMSM Using Current Compensation," IEEE Transactions on Applied Superconductivity, vol. 20, no. 3, pp. 10681071, 2010.

[4] K. Zhou, D. Wang, Y. Yang, and F. Blaabjerg, Periodic Control of Power Electronic Converters. 2016.

[5] M. S. Suleiman, A. A.-S. Mohammad, I. O. Georgios, and H. Babar, "Repetitive Current Control of an Interleaved Grid-Connected Inverter," in Power Electronic Converters for Microgrids: IEEE, 2014, p. 1
[6] M. Tang, A. Formentini, S. Odhano, and P. Zanchetta, "Design of a repetitive controller as a feed-forward disturbance observer," in IECON 2016 - 42nd Annual Conference of the IEEE Industrial Electronics Society, 2016, pp. 78-83.

[7] M. Tang, A. Gaeta, A. Formentini, and P. Zanchetta, "A Fractional Delay Variable Frequency Repetitive Control for Torque Ripple Reduction in PMSMs," IEEE Transactions on Industry Applications, vol. 53, no. 6, pp. 5553-5562, 2017.

[8] A. F. Mi Tang, Pericle Zanchetta, "Repetitive Observer Design for Torque Ripple Reduction in PMSM Drives," 2019 European Conference on Power Electronics and Applications (EPE), Genova, 2019 (accepted), 2019.

[9] M. Tang, A. Formentini, S. A. Odhano, and P. Zanchetta, "Torque Ripple Reduction of PMSMs using a Novel Angle-based Repetitive Observer," IEEE Transactions on Industrial Electronics, pp. 1-1, 2019.

[10] A. Galassini, G. L. Calzo, A. Formentini, C. Gerada, P. Zanchetta, and A. Costabeber, "uCube: Control platform for power electronics," in 2017 IEEE Workshop on Electrical Machines Design, Control and Diagnosis (WEMDCD), 2017, pp. 216-221. 